\title{
An attempt in the scope of the inner structure of human personality
}

\author{
Shamal Hussein Abu-Baker \\ Department of English, University of Human Development, Sulaimani/ Kurdistan \\ Email address: \\ shamalinternet@yahoo.com
}

\section{To cite this article:}

Shamal Hussein Abu-Baker. An Attempt in the Scope of the Inner Structure of Human Personality. International Journal of Literature and Arts. Vol. 2, No. 4, 2014, pp. 88-91. doi: 10.11648/j.ijla.20140204.11

\begin{abstract}
It can be said that basically the existence of human being consists of body \& soul. Body consists of many independent but interacting organs, each has its own structure, capability, \& function, \& the brain is the governor $\&$ the manager of the body. Likewise, human mental organization in the soul consists of some specific but interacting components, contacting \& communicating with each other. These components are (Needs, Psyche \& Mind), each one has its own properties \& function, \&, eventually; psyche bears the responsibility for the soul, directing soul \& body as a whole, deciding \& governing all behaviors (intentions \& actions) observed from a healthy human being.
\end{abstract}

Keywords: What Governs Human Being, Does Emotion Differ From Effervescence, \& Limits of Intention, Behaviour

\section{The Needs}

They are operating, independent \& neutral powers, \& continuous motifs, asking or requesting psyche for satisfaction, answer \& fulfillment, without determining or deciding any sort, way, quantity or quality of the answer that they ask psyche to achieve.

Psychological terms like (desire, aim, wish, appetite, impulse, motif, stimulus, goal, instinct, innate, inborn, etc.) may be some different manes for the same concept, \& may have the same set of functions in human personality structure, even if they have different names or positions according to different psychological approaches.

\subsection{Types of Needs}

1. Survival needs, consisting of :

a\ Physiological needs like (eating, drinking, sleeping, sex, etc.)

b $\backslash$ Security \& health needs like (self-preservation, protection, \& maintenance) from danger, frightening, deprivation, denial \& uncomfortable state of being.

2. Dignity needs, consisting of :

a) Social needs like (connection, agreement, commitment, satisfaction) \& (amity, friendship, social fondness, motherhood, etc)

b $\backslash$ Respectability needs like (self-esteem, recognition, respective being, acknowledging, acquisition, honor, fame, and self-knowledge). c $\backslash$ Self proof needs like (offering, potential, success, intrepidity, thinking, free doings, preference, perfectibility, approval, self-fulfillment, etc.).

Briefly, needs are a set of bodily \& spiritual motives, stimulating human strives to keep their continuity \& to be operational during life course, to enjoy a healthy biological life, to achieve a social prestige $\&$ a spiritual dignity.

So, needs can be educated, grown up carefully, directed $\&$ operated. Otherwise; they cannot be suppressed, ended, stopped, banned or given up. This aspect has its share in determining the orientation \& the framework of many human studies, such as politics, education, preaching, journalism, trade, etc.

\section{Psyche}

It is the second basic component. It is a self-knowing, aware, attentive \& always moving being, which tends to choose an option or offer more answers for continuous requests of the needs. It is the determiner of the number, way, sort, quantity \& quality of those answers, \& it freely responds as intentions \& actions to the needs. Psychological concepts like (self, person, id, subject and agent) may be different names for the same component.

\subsection{What is Will (Willpower-Volition)}

It is psyche's performance \& function within choice practicing at making decision. Absolute or free will is done 
deliberately by the psyche in intentions \& cannot be isolated from the material environment (Milieu), so one's "free will" will be restricted or limited by environment barriers \& comings, like limited bodily potential power and knowledge. Here is the point which declares the absolute willpower inside the psyche, \& the existence of the behavioral proportionality in the material milieu outside the psyche, when intentions are translated to behaviors.

\subsection{Psychic Potentials}

There are two lists of innate potentials opposite to each other, inside the psyche. Almost all psychological attitudes are results of choosing an item or more from one of these two lists that are mentioned bellow:

1. The list of good potentials: It contains items like (truth, optimism, love, bravery, self-confidence, contentment, sacrifice, content, medial, contribution, competition, acceptance, perseverance, forgiving, goodness, etc.), which lead to the realization of high morals when they are chosen by the psyche.

2. The list of evil potentials: It contains items like (lying, coward, aggression, greed, selfishness, rapidity, evilness, pessimism, ignorance, extremism, excessiveness, jealousy, etc.), which lead to the realization of low morals when they are chosen by the psyche.

These items in these two lists are just potentials, that is possible to psyche to choose or ignore them. Moreover; there are two heralds, decorators and adorners, or destroyers and ugly makers; calling for each item of these two lists, in order to be chosen by psyche, to become an intention and to be translated to a behavior through the parts of body.

The list of evil potentials has 'Inclination agent', and the list of good ones has 'caution Agent'. Each one of these, tries to decorate its own items, meanwhile each tries as well to make ugly or lovely the reverse items in the opposite list.

Thus, while psyche is selecting or ignoring one of their items, these agents show a passion of agreement or hatred, or an obsession of happiness or sadness. In other words, passions such as 'fineness or ugliness, happiness or sadness, praising or dispraising, love or hate, etc.' are just spectacles of Inclination or Caution agents to approach themselves to psyche within its operation -procedure- of selecting them.

Here one can conclude that;

+ Caution Agent: likes, to a great extent, dignity needs to be fulfilled, and to possess this fulfillment for long lasting. It calls to its list from this perspective and decorates its items to psyche.

+ Inclination Agent: likes, to a great extent, survival needs to be fulfilled, and to possess this fulfillment in an instantaneous, quick, and wide way, and decorates the items of this list to psyche in this way.

+ Moral and Ethical items are innate and potential.
Experiences, knowledge, milieu and sources of power are unable to create them from nonexistence, nor to remove them from existence. In other words, Morals are inner potentials and psyche has the full control and ability to select or ignore them within just a moment.

\subsection{Characteristics of Psyche}

1. Moving and dynamicity: That it does not stop or stay forever on a situation or a choice, but either instantly chooses an item of good potentials and so becomes a good doer, or instantly chooses an item of evil potentials and so becomes a bed doer. So it does not become one of these two, once and for ever, but continuously seeks answers for permanent requests coming from needs, and its changeability continues acting till the death.

2. Alertness and Consciousness: That it is aware of what inputs and outputs are there through the soul, which are revealed as intentions and behaviors at the responding process. Also the psyche knows about itself, its potentials and choices, ideas coming from mind, external and internal stimulus, and their pressure on it. So it directs them instantly and shows its attitudes towards them in such a way that it wants and chooses.

3. Independency: The psyche is independent and is fully free from being directed by needs, and they cannot specify any behavioral quality or quantity to the psyche. Needs are just motives, but the psyche is the free director and determiner of any quality or quantity of the answers.

Also mind could just give and show information and choices to the psyche, else the mind could not oblige or enforce the psyche to do something in a certain way. So the psyche can be regarded as the unique directing power in the personality.

4-Unknown orientation: That is the hundred percent prediction about psyche's decisions and resolutions in impossible. Intentions are hidden, and their certain behavioral amount can just be observed, in which analyses may approximately declare the content psyche's intentions, orientations and purposes, when they are repeated more and more. Else, to completely account for or predicate someone's intention, will and behavior; is out of the question, for it is not an experimental or observable matter. It is, as Chomsky says; "Human science- forming capacities simply do not extent to... any domain involving the exercise of will.", so it is completely free.

\subsection{Briefly}

+ Psyche has the competence and is responsible for all human intentions and behavior.

+ The psychic will and intention are free, absolute and hidden, but the act is the realized quantity, quality, and orientation which are proportional, limited and revealed. That is why the intention and psychic selection have a 
wider field of movement than practice and action.

\section{Mind "Heart"}

By mind or heart we don't mean the ordinary flesh organ known in Biology. It is a psychological term used in this writing, which is a part of the soul which is specialized for education and knowledge in human being.

The heart is the third basic component, which may be called by diverse psychological approaches and theories as "reason, mind, logic, ego, conscience, etc." Firstly it is a white page and an empty balance or scale, which is then occupied by the experiences, information and data coming from sensory organs, and becomes a measurement for proportional "benefit-loss" or "good-bad" values. It continues progressing, improving, getting formation and completeness by passing the time, and accumulated experiences. It underlies the psyche, stimulated and consulted by the psyche about selected and chosen things and phenomena. Here, the heart notifies the psyche about any expected choice or unexpected coming event.

If the psyche takes in the consideration heart's notification, heart's attitude is an ordinary calm one. But when the psyche neglects or delays it, the heart tries to prove its notification and to fortify it by showing a certain effervescence like (anger, emphasize, emphasize, heedfulness, etc), which are different from emotions coming from both good and evil potential lists.

Emotions during psyche's decisions, are dual, opposite , absolute amount of appealing passions, such as the presence of dual emotions together, like ( love and hate, pride and modesty, happiness and sadness) as potentials which can quickly, by the psyche.

But Effervescences are unique, lonely, proportional amount of warnings from mind to the psyche during psyche's decisions, such as the presence of (anger, caution or fear) which are not accompanied by (calmness, trust, security) .Psyche could control or change the tension and the direction of a certain effervescence in a longer period of time and effort according to the degree and kind of this effervescence. Why these defenses exist between them?

The needs and their answers are many, so the psyche is always busy with them. Here the emotions are always there, appealing to decorate or make ugly the attractions for a certain response.

So the emotions are many in number and occurrence. But usually the psyche listens and takes in the consideration the mind's (heart's) logical advices and counsels. Occasionally the psyche neglects or delays these counsels due the free nature of its capability, here the heart uses its effervescence state and warning to reinforce its logical conclusion and counsels about the needs and the available responses. That is why the number and occurrence of the effervescence are less, and more occasional then the emotions' ones.

\subsection{The Relationship between Heart and Brain}

Although heart (mind) and brain are two different beings, there is a continuous and direct relationship between them, which has become the linking bridge between soul and body concerning knowledge.

Brain is the center of recording, preserving, and representing human information and data about (Nouns, the relationship between Nouns). Heart (mind) is the director of this center and the operator. Brain is a big library, while heart is the person who deals with it, benefits from it, provides it with new sources, or removes from it some sources. Heart depends on these nouns and relationship in its reasonable and logical processes. Thus one can assume that brain, from the birth time, is an innate balancing device for balancing the inputs, and the empty store for data and information. So mental processes are acquirable, not innate, nor biological, but the capability of balancing different sensory data and inputs is innate and instinctive, for instant; processing and recognizing the balance state of inputs like sounds, colors, touches, movements, shapes, structures, etc, even language inputs in the level of sounds, grammar, etc.

\subsection{Functions of Heart}

There were just two types of psychic attitudes in human's intentions and behavior, either a psyche which commands doing bad, or a psyche which blames its previous bad commands and tends to do good. So in a certain time, psyche is either this or that. But heart has a lot of attitudes, and can be described in various states like (trig, core, wise, denial, hard, secure, harsh, pure, marked, silent, changeable, soft, locked, graceful, tremble, coined, etc.), also as having various rules like (education, intellectuality, scholar, recording, imagination, conceive, predicate, reasoning, etc.).

\subsection{The Intention and the Behavior}

Intentions and purposes are the results of the final decisions or determinations of psyche concerning a choice or a selection, which then the psyche commands the heart, and within this, it commands the whole brain, body and soul to translate this intention to a certain behavior. This represents that perfect amount of the intention, transformed to an actual physical ratio of the behavior.

- Intention and purpose by the psyche: is an absolute, unlimited, and an independent phenomenon which occurs in the time of selection, and there is not any external or internal restriction in front of it, and God has allowed it to have such nature.

- Knowledge by the heart (mind): is a phenomenon which has been limited by experiences, experimental, etc.

- Power, capability, competence and force by the body:

- There are limited and proportional phenomena restricted by barriers like; lack of means, illness, 
weakness, limited size of body, limited financial potentials, authority, etc.

- So the intention is absolutely free and completely independent, while the behavior, which is the actual translated intention to the reality by the means of knowledge and power, is proportional . That is why we could clearly observe that the intention is emphasized on, after human's awareness and religious instructions before emphasizing on the amount of benefit or damage that may occur by a certain human behavior, and also the intention affects the amount and type of a certain punishment applied for a certain deed.

\subsection{Conclusion}

Human being is neither an angle, nor a devil; he has a nature of moving and free dynamic selecting ability to choose from good and evil moral potential lists. Thus someone is called or recognized as a good or evil person, when his /her apparent or outward deeds and morals are almost good or evil.

This means that a good doer person is not someone whose all deeds, thoughts, and intentions are good, and he/she is not pure from any evil or mistaken aspect. Also an evil doer person is not an absolute owner of evil deeds, thoughts, and intentions.

To shift from a physiological state or attitude to another, this could be done at once by an instant decision, but to reannounce yourself in the society by your new decision, direction, and physiological state is a slow process, demanding much more time and effect, to prove and describe your new state again within repeating a lot of deeds and attitudes in a lot of occasions in the society.

\section{References}

[1] Alija Izetbegović.Islam between East and West.

[2] Anne Tyler. An Introduction to Psychology. Translated by Essa Samaan. 1996.

[3] Dale Carnegie. How to Win Friends and Influence People. Translated by Abdulmuneem Al-Zabady. Baghdad. 1987.

[4] Dr. Muhammed Al-Tikrity. The Psychological Engineering. 1998.

[5] Dr. Mustafa Swaif. The Philosophy, Present, and Future of Psychology as a Social Entity. 2000.

[6] G. F. Denzel. Philosophical Psychology. Translated by Saeed Ahmed Al-Haleem. 1986.

[7] J. K. Flogel. Psychology in a Century. Translated by Lutfy Fateem.

[8] Jean Piaget. 60 Years Research in Children's Mind. Translated by Dr. Hassan Ahmed Essa. Al-Araby Journal. 1982.

[9] John Loess. Human Being...The Unique Creature! Translated by Dr. Salih Jawad Al-Kadhim. 1981.

[10] Margaret Donaldson. Children's Minds. Translated by Dr. Adil Abdulkareem Yaseen. 1989.

[11] Qasim Hussein Sailh. Who is Human being? 1987.

[12] Researches of the Psychology Forum. International Institute of Islamic Thoughts. 1993.

[13] The Holly Qur'an. 